\title{
An Examination of the Equity Market Price Linkage Between Australia and the European Union Using Leveraged Bootstrap Method
}

\author{
Abdulnasser Hatemi-J and Eduardo D. Roca ${ }^{*}$
}

\begin{abstract}
We examine the equity market price interaction between Australia and the European Union - represented by the UK, Germany and France, based on the Toda-Yamamoto (1995) causality test which we bootstrap with leveraged adjustments. We use weekly MSCI data covering the period 1988 to 2001, which we divided into two sub-periods to allow for a structural break arising from the ERM crisis of 1992. Our results show that, during the period before the ERM crisis, no significant causal links exist between Australia and any of three EU countries. During the period after the ERM crisis, Australia also had no causal links with Germany and France but it had with the UK with the causality running from the UK to Australia but not vice-versa. Thus, Australian investors may find the German and French, but not the UK, equity markets, as attractive venues for their international diversification. German and French, but not the British, investors may also obtain the same benefit from the Australian equity market.
\end{abstract}

Running title: Equity Market Price Linkages

JEL Classification: G15, G11

Keywords: Equity Market Integration, Leveraged Bootstrap, Causality, European Union

\footnotetext{
* The first named author is with the University of Skövde, Skövde, Sweden while the second named one is with the School of Accounting, Banking and Finance, Griffith University, Nathan, Queensland, Australia. Address correspondence to Dr. Eduardo D. Roca, School of Accounting, Banking and Finance, Griffith University, Nathan, Queensland, Australia 4111; Email: E.Roca@mailbox.gu.edu.au; Tel: (61 7) 3875 7583; Fax: (61 7) 38757760.
} 


\title{
An Examination of the Equity Market Price Linkage Between Australia and the European Union Using Leveraged Bootstrap Method
}

\begin{abstract}
We examine the equity market price interaction between Australia and the European Union - represented by the UK, Germany and France, based on the Toda-Yamamoto (1995) causality test which we bootstrap with leveraged adjustments. We use weekly MSCI data covering the period 1988 to 2001, which we divided into two sub-periods to allow for a structural break arising from the ERM crisis of 1992. Our results show that, during the period before the ERM crisis, no significant causal links exist between Australia and any of three EU countries. During the period after the ERM crisis, Australia also had no causal links with Germany and France but it had with the UK with the causality running from the UK to Australia but not vice-versa. Thus, Australian investors may find the German and French, but not the UK, equity markets, as attractive venues for their international diversification. German and French, but not the British, investors may also obtain the same benefit from the Australian equity market.
\end{abstract}

Running title: Equity Market Price Linkages

JEL Classification: G15, G11

Keywords: Equity Market Integration, Leveraged Bootstrap, Causality, European Union 


\section{Introduction}

Because of the economic significance of the EU, Australian investors have a reason to look at the EU as a possible venue for international diversification. On the other hand, due to the impressive economic performance of Australia especially since the occurrence of the Asian financial crisis, EU investors may also consider Australia as a possible component of their international portfolio ${ }^{1}$. But as is well-known in portfolio theory, the benefits to be gained from international diversification depend on the correlation between markets. As long as the correlation is less than one, then it pays to diversify (Markowitz, 1959). Correlations, however, are not a reliable guide. Unconditional correlations have been found to be time varying (see, for example, Solnik, et. al, 1996). The unconditional correlation between any two markets can be low and therefore provides international diversification benefits but this can disappear over time if the two markets are found to have a stable long-term relationship. Hence, total reliance on unconditional correlations can be misleading. In order to understand the stability of these correlations, it is important to know the causal interaction of the markets.

In this paper, we examine the causal relations between the equity markets of Australia and the three largest EU economies. A number of studies have examined the structure of interdependence between stock markets but to the best of our knowledge, none has particularly focused on this set of equity markets. There have been studies on Australia's financial linkages but these studies mainly deal with markets other than the EU. For instance, Roca (1999) investigated Australia's stock market linkages with the US, UK, Japan, Hong Kong, Korea, Taiwan and with the ASEAN countries of Singapore, Malaysia, Indonesia, Thailand, and the Philippines. There is one study on Australia's financial market linkage with the EU, the one by McNelis (1993), but this study only includes the UK and Germany but not France.

Furthermore, previous studies have utilised asymptotic methods in the estimation and testing of parameters. It is well-known that these methods lose power when the variables are characterised by non-normal probability distributions and the presence of time varying volatility or ARCH effects. Since it is well-established that this is the case with financial time series, we therefore use a different approach. We utilise a bootstrapping methodology which is well-recognised to yield more reliable estimates of parameters. As will be discussed later with more details in Section 4 of the study, we utilise the Toda-Yamamoto (1995) test, which we bootstrap following Hacker and Hatemi-J (2002). As far as we know, this method has not been applied before. We also apply a new information criterion, called the Hatemi-J criterion, for determining the lag length. This criterion has been shown in Hatemi-J (2002) to be superior to existing information criteria, particularly for integrated variables. Thus, our study can generate more reliable results and provide a robust contribution to the literature.

In addition to the importance of the study to investors in terms of international portfolio diversification, the results of the study would also be useful to financial regulators and policy makers in relation to the issue of contagion or spill-over risk. If, for instance, it is found that the EU Granger-causes Australia, then there is the risk of contagion for Australia and thus, this should be a cause for concern to Australian regulators. 
The rest of the paper is organised as follows. Section 2 provides a brief review of the literature while Section 3 presents a discussion of the characteristics of the data and their implications in terms of portfolio diversification. Section 4 discusses the methodology and Section 5 presents the empirical results. Finally, conclusions are provided in the last section.

\section{Previous Studies on Equity Market Linkages}

The issue of financial market, particularly equity market, price linkages has been examined quite extensively in the literature. However, there is no clear conclusion as to the extent of these linkages. Some studies have found that equity markets are integrated (see, for instance, Agmon, 1972; Wheatley, 1988; Hamao, et. al., 1990; Espitia and Santamaria, 1994, among others) while others reported that equity markets are segmented (see, for instance, Grubel, 1968; Makridakis and Wheelwright, 1974; Adler and Dumas, 1983; Dwyer and Hafer, 1988; Smith, et. al., 1995). Thus, there is scope for further research on equity markets interaction.

There is also no clear agreement in the literature as to which markets are significantly linked although the results seem to point to the existence of a linkage between certain groups of equity markets based on some unifying or common factor, such as close regional, economic, and geographical relationships. To, et. al. (1994) found the following clusters: Japan and Asian emerging markets, and the UK and African emerging markets. Hillard (1979) discovered a close association among intracontinental markets during the oil crisis of 1973 while Jorion (1989) reported a high degree of linkage among European continental markets. An Anglo-Saxon cluster was also reported by Jorion (1989). Thus, there is a need to examine other possible market clusters. Since Australia and the EU countries are engaged in significant economic interaction in terms of trade (DFAT 2001), there is a basis for suspecting the existence of a significant equity market linkage between them.

There is, however, consensus in the literature that the US equity market is the most influential stockmarket in the world (see, for instance, Chowdhury, 1994 and Masih and Masih, 1999, among others). There is overwhelming evidence that the United States leads other markets, with the exception of such markets as Korea, Taiwan and Thailand (see, for example, Eun and Shim, 1989; Fischer and Palasvirta, 1990). But there are some studies such as those of Granger and Morgenstern (1970) and Hillard (1979) that reported no lead/lag relationships among markets.

Empirical results of studies that include Australia show that Australia seems to be significantly influenced by the US and UK markets. Malliaris and Urrutia (1992), for instance, using Granger-causality tests, found the US to be leading Australia during the stock market crash of 1987. This is also confirmed by the results of Eun and Shim (1989). With the use of variance decomposition analysis, they found that the US and the UK explained 15\% and 6\%, respectively, of Australia's forecast error variance. Based on VDC analysis, Park and Fatemi (1993) also had the same finding as Eun and Shim (1989) in relation to the relationship between Australia and the US and the UK. Other studies that confirm these results are those of Janakiramanan and Lama (1998), Sheng and Tu (2000) and McNelis (1993). 
These findings, however, should be taken with caution. As already stated earlier, these studies have mainly utilised statistical and econometric methods which are based on asymptotic methods. Again, as also pointed out previously, this can lead into biased inference in the presence of non-normality and ARCH effects in the data, which is well-known to characterise financial variables. The present study addresses this gap in the literature through the use of the Toda-Yamamoto (1995) causality test which we bootstrap and also through the application of a new, more reliable method for determining the lag order of variables (Hatemi-J, 2002). Thus, the present study provides a significant contribution to the existing literature.

\section{Risk, Return and Distributional Properties of Each Market}

We use weekly MSCI data, in USD, for the Australian, UK, German and French equity markets. The MSCI is well-known for its reliability and avoidance of doublelisting. It covers at least $60 \%$ of the capitalisation of each market and only includes stocks, which are liquid. The use of weekly data avoids the problem of having too much noise associated with the use of daily data (Bailey and Stulz, 990), as well as the issue of non-synchronous trading times.

We examine the period 1988 to 2001. During this period, trade interaction between Australia and the EU increased significantly (DFAT, 2001). Furthermore, significant developments occurred in both the Australian and EU equity markets which have led to the increasing globalisation of these markets, such as deregulation and liberalisation in the case of Australia ${ }^{2}$ and increasing integration in the case of the $\mathrm{EU}^{3}$ markets. Furthermore, in the case of the EU, there is one very significant event which occurred during this period - the European Rate Mechanism (ERM) crisis in $1992^{4}$. During this crisis, the UK dropped out of the ERM while the bands for which the EU currencies could fluctuate were widened. We allow for a structural break in the data to take the ERM crisis into account by dividing the sample period into two sub-periods ${ }^{5}$. The first sub-period covers the first week of January 1988 to the second week October 1992 while the second sub-period corresponds to the third week in October 1992 until last week August 2001.

Table 1 below presents the returns and risks associated with each market and the contemporaneous correlations between the Australian and each of the EU markets. Based on the coefficient of variation (CV), the EU markets perform better than the Australian market since each of them has a lower risk per unit of return compared to Australia. This is the case for both periods. Returns and risk for each market vary over the two sub-periods with the coefficient of variation increasing in the second period, which implies that risk-adjusted returns have decreased during this period. In terms of the correlation between Australia and each of the EU market, all are less than one, which signifies that there is the potential benefit to be obtained by Australian investors diversifying into the EU and EU investors diversifying into Australia ${ }^{6}$. Since the correlations between Australia and France and Australia and Germany are lower than those between Australia and the UK, then the potential diversification benefit for Australian investors is higher if they invest in the French and German markets than in the UK markets. This also indicates that the French and German investors would benefit more than UK investors by diversifying into the Australian market. The correlation between Australia and each of the EU countries has decreased in the second period, which indicates that the potential diversification 
benefits have increased. Caution, however, must be exercised in accepting this conclusion. There is a need to undertake a causality analysis between the markets which can better capture the long-term association between the Australian and each of the EU market. We undertake this by using the Toda-Yamamoto (1995) causality test.

Table 1: Risk, Return and Contemporaneous Correlations

\begin{tabular}{|c|c|c|c|c|}
\hline MARKET & $\begin{array}{l}\text { RETURNS } \\
\text { (MEAN) }\end{array}$ & $\begin{array}{c}\text { RISK } \\
\text { (STANDARD } \\
\text { DEVIATION) }\end{array}$ & $\begin{array}{c}\text { RISK PER UNIT } \\
\text { OF RETURN } \\
(\mathrm{CV})\end{array}$ & $\begin{array}{l}\text { CONTEMPORANEO } \\
\text { US CORRELATION* }\end{array}$ \\
\hline \multicolumn{5}{|c|}{ First Sub-Period (1988:01:W1-1992:10:W2) } \\
\hline Australia & $0.126 \%$ & $3.418 \%$ & 27.12 & \\
\hline France & $0.368 \%$ & $2.792 \%$ & 7.59 & 0.379 \\
\hline Germany & $0.258 \%$ & $2.976 \%$ & 11.53 & 0.377 \\
\hline UK & $0.253 \%$ & $2.873 \%$ & 11.36 & 0.436 \\
\hline \multicolumn{5}{|c|}{ Second Sub-Period (1992:10:W3-2001:08:W4) } \\
\hline Australia & $0.094 \%$ & $2.379 \%$ & 25.30 & \\
\hline France & $0.160 \%$ & $2.505 \%$ & 15.65 & 0.258 \\
\hline Germany & $0.159 \%$ & $2.692 \%$ & 16.93 & 0.306 \\
\hline UK & $0.130 \%$ & $2.059 \%$ & 15.84 & 0.435 \\
\hline
\end{tabular}

*Between Australia and each EU country of France, Germany and UK. CV stands for coefficient of variation.

Further descriptive statistics are presented in Table 2, which show the existence of non-normality in the data. The null hypothesis of normality is rejected for each variable in each period except for Australia in the second sub-period. It seems that kurtosis is the main reason for non-normality. We also tested for multivariate normality in each sub-period. The estimated statistic was 347.67 in the first period and 325.24 in the second period. These values are higher than the critical values at the one percent significance level. Thus, the null hypothesis of normality can strongly be rejected in both sub-periods. Also we tested for multivariate ARCH for each subperiod. The estimated test value was 357.66 in the first sub-period and 336.89 in the second sub-period. These values are much higher than the critical values at the one percent significance level, which implies that the null hypothesis of no ARCH effects is strongly rejected in each sub-period. Therefore, given this situation, in order to obtain more accurate results, we bootstrap with leveraged adjustments the TodaYamamoto (1995) causality test. This is explained in a more detailed manner in the next section. 
Table 2: Descriptive Statistics and Contemporaneous Correlations

\begin{tabular}{||c|c|c|c|c|c||}
\hline \hline MARKET & MIN & MAX & SKEWNESS & KURTOSIS & JB \\
\hline \multicolumn{7}{|c||}{ First Sub-Period (1988:01:W1-1992:10:W2) } \\
\hline Australia & -36.62 & 9.535 & -3.207 & 33.711 & $1870.018^{* * *}$ \\
\hline France & -11.71 & 9.083 & -0.311 & 4.199 & $34.660^{* * *}$ \\
\hline Germany & -12.13 & 8.591 & -0.432 & 3.855 & $28.079^{* * *}$ \\
\hline UK & -23.76 & 10.663 & -1.188 & 13.407 & $2195.762^{* * *}$ \\
\hline \multicolumn{7}{|c||}{} \\
\hline Australia & -7.26 & 8.114 & -0.026 & 3.319 & 2.018 \\
\hline France & -9.02 & 10.867 & 0.096 & 4.157 & $26.829^{* * *}$ \\
\hline Germany & -12.45 & 12.675 & -0.203 & 5.584 & $132.541^{* * *}$ \\
\hline UK & -8.14 & 7.217 & 0.199 & 3.669 & $11.762^{* * *}$ \\
\hline
\end{tabular}

Notes:

(a) JB denotes Jarque-Bera test for normality.

(b) The notation $* * *$ means that the null hypothesis of normality is rejected at the one percent significance level.

\section{Methodology}

In this section we describe the methodology that is utilised to conduct the empirical analyses of this paper. We start with describing the Perron (1989) test for unit roots. Next, we define the Toda and Yamamoto (1995) test statistics for Granger (1969) causality between non-stationary (integrated) variables. Since the choice of lag order is a central issue in this aspect we will also define a new information criteria that performs well for non-stationary data. In the next stage, we present the bootstrap simulation technique that is used to generate our own critical values for tests of Granger causality.

It is well established in the literature that it is important to check the time series properties of the underlying data in order to avoid spurious and misleading inference. It is also well known that standard tests for unit roots have low power if structural breaks have occurred during the period of study. In order to take into account the effect of a potential structural break arising from the ERM crisis of 1992 we make use of a test suggested by Perron (1989) to test for the integration order of the variables. This test allows for a structural break in both the mean value and the deterministic trend of the variable under investigation. The Perron (1989) test for unit roots of variable $z$ is based on the following regression:

$$
z_{t}=c_{1}+c_{2} D_{t}+d_{1} t+d_{2} D_{t} t+g J_{t}+z_{t-1}+\sum_{i=1}^{m} b_{i} \Delta z_{t-i}+\varepsilon_{t}
$$

where $t=$ the time period (the linear trend term), $D_{t}$ is a dummy variable that takes value zero for the time period before break and one for the rest of the period, $J_{t}$ is equal to one if the time period $t$ is the first period after that of the structural break, and is zero otherwise. $\Delta$ is the first difference operator and $\varepsilon_{t}$ represents a white noise error term. The null hypothesis of a unit root is $\gamma=1$. The optimal number of lagged differences $(m)$ is chosen by including more lags until the null hypothesis of no serial 
autocorrelation for $\varepsilon_{t}$ is not rejected by the Ljung-Box test at the $5 \%$ significance level.

The next step in our study is to investigate the causal relationship between the variables. ${ }^{7}$ Consider the following vector autoregressive model of order $p, \operatorname{VAR}(p)$, to allow for dynamic interaction between variables of interest in a system perspective:

$$
y_{t}=v+A_{1} y_{t-1}+\ldots+A_{p} y_{t-p}+\varepsilon_{t},
$$

where $y_{t}, v$, and $\varepsilon_{\mathrm{t}}$ are $n$-dimensional vectors ( $n$ is the number of variables in the model, which is four in our case) and $A_{r}$ is an $n \times n$ matrix of parameters for lag $r$. A crucial issue in this regard is the choice of the optimal lag order $(p)$ since all inference is based on the chosen lag order. To this end, we apply the Hatemi-J (2002) information criterion, which is described below:

$$
H J C=\ln \left(\operatorname{det} \widehat{\Omega}_{j}\right)+j\left(\frac{n^{2} \ln T+2 n^{2} \ln (\ln T)}{2 T}\right), \quad j=0, \cdots, p \text {, }
$$

Here ln signifies the natural logarithm, $\operatorname{det} \widehat{\Omega}_{j}$ is the determinant of the estimated variance and covariance matrix of the error terms in the VAR model for lag order $j, n$ stands for the number of variables and $T$ is the number of observations used to estimate the VAR model. Hatemi-J shows through Monte Carlo simulation experiments that this new information criterion performs well, particularly if variables are integrated. The lag order that is minimizing equation (3) is the optimal lag order.

Toda and Yamamoto (1995) suggest the following augmented VAR $(p+d)$ model to be used for tests of causality if the variables are integrated:

$$
y_{t}=\hat{v}+\hat{A}_{1} y_{t-1}+\ldots+\hat{A}_{p} y_{t-p}+\ldots+\hat{A}_{p+d} y_{t-p-d}+\hat{\varepsilon}_{t}
$$

where the circumflex above a variable represents its OLS estimate, a notation that continues throughout this paper. $d$ is equal to the integration order of the variables.

The $k$ th element of $y_{t}$ does not Granger-cause the $j$ th element of $y_{t}$ if the following hypothesis is not rejected:

$$
H_{0} \text { : the row } j \text {, column } k \text { element in } A_{r} \text { equals zero for } r=1, \ldots, p \text {. }
$$

It should be mentioned that the parameters for the extra lag(s), i.e., $d$, are unrestricted in testing for Granger causality. According to Toda and Yamamoto (1995), these unrestricted parameters ensure that the asymptotical distribution theory can be applied. In order to describe the Toda-Yamamoto test statistic in a compact way, let us define the following denotations for a sample size $T$ :

$$
\begin{aligned}
& Y:=\left(y_{1}, \cdots, y_{T}\right) \quad(n \times T) \text { matrix, } \\
& \hat{D}:=\left(\hat{v}, \hat{A}_{1}, \cdots, \hat{A}_{p}, \cdots, \hat{A}_{p+d}\right) \quad(n \times(1+n(p+d))) \text { matrix, }
\end{aligned}
$$




$$
\begin{aligned}
& Z_{t}:=\left[\begin{array}{c}
1 \\
y_{t} \\
y_{t-1} \\
\vdots \\
y_{t-p-d+1}
\end{array}\right]((1+n(p+d)) \times 1) \text { matrix, for } t=1, \ldots, T \text {, } \\
& Z:=\left(Z_{0}, \cdots, Z_{T-1}\right) \quad((1+n(p+d)) \times T) \text { matrix, and } \\
& \hat{\delta}:=\left(\hat{\varepsilon}_{1}, \cdots, \hat{\varepsilon}_{T}\right) \quad(n \times T) \text { matrix. }
\end{aligned}
$$

By means of this notation, the estimated $\operatorname{VAR}(p+d)$ model is written compactly as:

$$
Y=\hat{D} Z+\hat{\delta}
$$

We continue by estimating $\hat{\delta}_{U}$, the $(n \times T)$ matrix of estimated residuals from the regression (6) without imposing the null hypothesis of none causality. Then the matrix of cross-products of these residuals are computed as $\mathrm{S}_{U}=\hat{\delta}_{U}{ }^{\prime} \hat{\delta}_{U}$. Let us now define $\beta=\operatorname{vec}\left(v, A_{1}, \cdots, A_{p}, 0_{n \times n d}\right)$ and $\hat{\beta}=\operatorname{vec}(\hat{D})$, where vec signifies the column-stacking operator and $0_{n \times n d}$ denotes a zero matrix with $n$ rows and $n \times d$ columns. The modified Wald (MWALD) test statistic, introduced by Toda-Yamamoto, for testing the null hypothesis of non-Granger causality is then written as

$$
M W A L D=(C \hat{\beta})^{\prime}\left[C\left(\left(Z^{\prime} Z\right)^{-1} \otimes S_{U}\right) C^{\prime}\right]^{-1}(C \hat{\beta}) \sim \chi_{p}^{2}
$$

where the notation $\otimes$ is the Kronecker product (element by element multiplication), and $C$ is a $p \times n(1+n(p+d))$ matrix. Each of the $p$ rows of $C$ is associated with the restriction to zero of one parameter in $\beta$. The elements in each row of $C$ acquire the value of one if the related parameter in $\beta$ is zero under the null hypothesis, and they get the value of zero if there is no such restriction under the null. It should be mentioned that none of the rows in $C$ are associated with restrictions on the last $n^{2} \times d$ elements in $\beta$, which correspond the $0_{n \times n d}$ matrix noted above. Using these notations, the null hypothesis of no causality can be expressed as

$$
H_{0}: C \beta=0
$$

The MWALD test statistic is asymptotically $\chi^{2}$ distributed with the number of degrees of freedom is equal to the number of restrictions to be tested (equal to $p$ in this case). However, the simulation experiments conducted by Hacker and Hatemi-J (2002) demonstrate that the Toda-Yamamoto test statistic that is based on asymptotical distributions overrejects the null hypothesis. The authors suggest utilizing bootstrap distributions instead of asymptotical chi-square distributions. Their paper shows that the inference based on leveraged bootstrap distributions is much more precise, especially when the data generating process is characterized by non-normality or ARCH effects. On these grounds, we will make use of the bootstrap simulation techniques to produce our own critical values in causality tests. Another advantage of bootstrapping is that it is based on the empirical distribution of the underlying data set and it is not sensitive to normal distribution. Since the probability of extreme events in the financial markets is usually much higher than the normal distribution, the 
application of bootstrap seems to be necessary. Another issue that is important to take into account is the fact that in financial markets usually the volatility is time dependent (the ARCH effects exist). In order to guarantee that the presence of ARCH effects does not render bias in estimation results, we use the leveraged bootstrap as suggested by Davison and Hinkley (1999) and Hacker and Hatemi-J (2002).

The bootstrap technique, which was originally introduced by Efron (1979), is based on resampling the data set to estimate the distribution of a test statistic. Using this distribution can decrease bias in inference by providing more precise critical values. For the bootstrap simulations we first estimate regression (6) with the restriction for the null hypothesis of no Granger causality on one of the included equations. For each bootstrap simulation we generate the simulated data, $y_{t} *$, based on the coefficient estimates from this regression, $\hat{v}, \tilde{A}_{1}, \cdots, \tilde{A}_{p}$; the original $y_{t-1}, \ldots, y_{t-p}$ data; and $\widetilde{\varepsilon}_{t} *$ (the bootstrapped residuals). These residuals are based on $T$ random draws with replacement from the regression's modified residuals, each with equal probability of $1 / T$. The mean of the resulting set of drawn modified residuals is subtracted from each of the modified residuals in that set. This adjustment is done to make sure that the mean value of the bootstrapped residuals is zero. The modified residuals are the regression's raw residuals modified to have constant variance, through the use of leverages. $^{8}$

By conducting the bootstrap simulation 1000 times and then producing the MWALD test statistic each time, we can generate the empirical distribution for the MWALD test statistic. Subsequent to these 1000 estimations we find the $(\alpha)$ th upper quantile of the distribution of bootstrapped MWALD statistics and attain the $\alpha$-level "bootstrap critical values" $\left(c_{\alpha}^{*}\right)$. We generate the bootstrap critical values for $1 \%, 5 \%$ and $10 \%$ significance levels. The next step is to calculate the MWALD statistic using the original data (not the bootstrapped simulated data). Then, the null hypothesis of no Granger causality is rejected based on bootstrapping if the actual MWALD is greater than $c_{\alpha}^{*}$. The simulations are conducted by programming in GAUSS. ${ }^{9}$

\section{Empirical Results}

Prior to causality analysis, we conduct the Perron (1989) test for unit roots on the data. Results from these tests are presented in Table 3. For the null hypotheses of I(1), i. e. integration of the first order, the estimated test statistics are found to be less than the critical values at any conventional significance level. Thus, the null hypothesis that each variable is I(1) cannot be rejected. However, the null hypothesis that each variable is $I(2)$ is rejected at the one percent significance level. Hence, the evidence shows that each variable contains one unit root. Thus, we have to take into account the integration properties of the data in order to avoid spurious and invalid inference.

We also tested for parameter stability by applying the Chow (1960) multivariate test. The period for a structural break was the second week in October 1992 arising from the ERM crisis of 1992. The results showed that the null hypothesis of no structural break could be rejected even at the one percent significance level. To allow for the 
possibility that the economic process has changed during the sample period we make use of sub-periods.

Table 3: Test for Unit Roots Using the Perron test.

\begin{tabular}{||c|c|c|c||}
\hline $\mathrm{H}_{0}: \mathrm{I}(1), \mathrm{H}_{1}: \mathrm{I}(0)$ & TEST VALUE & $\mathrm{H}_{0}: \mathrm{I}(2), \mathrm{H}_{1}: \mathrm{I}(1)$ & TEST VALUE \\
\hline $\mathrm{SP}_{\mathrm{AUS}}$ & -3.69 & $\mathrm{SP}_{\mathrm{AUS}}$ & $\begin{array}{c}-27.83 * * * \\
(0)\end{array}$ \\
\hline $\mathrm{SP}_{\mathrm{FRA}}$ & -2.64 & $\mathrm{SP}_{\mathrm{FRA}}$ & $-5.60 * * *$ \\
& $(17)$ & & $(16)$ \\
\hline $\mathrm{SP}_{\mathrm{GER}}$ & -1.84 & $\mathrm{SP}_{\mathrm{GER}}$ & $-7.65^{* * *}$ \\
& $(14)$ & & $(13)$ \\
\hline $\mathrm{SP}_{\mathrm{UK}}$ & -1.52 & $\mathrm{SP}_{\mathrm{UK}}$ & $-28.72 * * *$ \\
& $(0)$ & & $(0)$ \\
\hline
\end{tabular}

Notes:

(a) The critical value is -4.78 and -4.17 at the $1 \%$ and $5 \%$ significance level, respectively.

(b) The notation $* * *$ implies significance at the one percent significance level.

(c) The numbers in the parentheses indicate the number of lags required to remove potential autocorrelation in the Perron regression (equation 1) at the 5\% significance level using the Ljung-Box test.

The results for the Granger causality test are presented in Table 4. As can be seen, during the first sub-period, no significant causal links exist between Australia and the EU because the estimated test is very much less than the critical values generated by leveraged bootstrap simulation techniques. After the ERM crisis, i.e. for the second sub-period, still no significant causal links exist between Australia and the countries of Germany and France. The estimated values are still very much less than the bootstrap critical values. However, it had one with the UK with the causality running from the UK to Australia but not vice versa.

These results provide confirmation to the earlier finding of the existence of diversification benefits for Australian investors and French and German investors arising from the low correlation between Australia and the French and German markets. However, the correlation of less than one between Australia and the UK is not confirmed to lead to international diversification benefits as it has been found that the UK Granger-causes Australia in the long-term. These results also concur with findings of previous studies, e.g. Roca (1999), McNelis (1993), Eun and Shim (1989).

Thus, the ERM crisis has changed the fundamental relationship between the UK and Australia but not that of Australia and the other EU countries of Germany and France. During the ERM crisis, the UK pulled out of the ERM arrangement. As a result of this, the UK has become more economically independent from the EU and may have become more involved with other markets such as Australia. Previous studies have explained the UK and Australia financial linkages as being due to a commonwealth effect, i.e., Australia and the UK being members of the Commonwealth group of countries (see Eun and Shim, 1989). This implies that for purposes of international diversification, Australia offers potential benefits to German and French, but not to British, investors while the German and French markets but not the UK market offer the same benefits to Australian investors. Since the estimated test values are very 
much way below the bootstrap values, these conclusions can be sustained even in the presence of transaction costs.

Table 4: Results of Causality Test Based on Bootstrap Simulation Techniques

\begin{tabular}{|c|c|c|c|c|}
\hline $\begin{array}{l}\text { THE NULL } \\
\text { HYPOTHESIS }\end{array}$ & $\begin{array}{c}\text { THE } \\
\text { ESTIMATED } \\
\text { TEST VALUE } \\
\text { (MWALD) }\end{array}$ & $\begin{array}{c}1 \% \\
\text { BOOTSTRAP } \\
\text { CRITICAL } \\
\text { VALUE }\end{array}$ & $\begin{array}{c}5 \% \\
\text { BOOTSTRAP } \\
\text { CRITICAL } \\
\text { VALUE }\end{array}$ & $\begin{array}{c}10 \% \\
\text { BOOTSTRAP } \\
\text { CRITICAL } \\
\text { VALUE }\end{array}$ \\
\hline \multicolumn{5}{|c|}{ First Sub-Period (1988:01:W1-1992:10:W2) } \\
\hline $\begin{array}{c}\mathrm{SP}_{\mathrm{FRA}} \neq> \\
\mathrm{SP}_{\mathrm{AUS}}\end{array}$ & 0.136 & 6.904 & 3.470 & 2.602 \\
\hline $\begin{array}{c}\mathrm{SP}_{\mathrm{GER}} \neq> \\
\mathrm{SP}_{\mathrm{AUS}}\end{array}$ & 0.665 & 6.485 & 4.034 & 2.705 \\
\hline $\mathrm{SP}_{\mathrm{UK}} \neq>\mathrm{SP}_{\mathrm{AUS}}$ & 1.011 & 5.827 & 3.915 & 2.958 \\
\hline $\begin{array}{c}\mathrm{SP}_{\mathrm{AUS}} \neq> \\
\mathrm{SP}_{\mathrm{FRA}}\end{array}$ & 0.007 & 6.703 & 4.283 & 3.080 \\
\hline $\begin{array}{c}\mathrm{SP}_{\mathrm{AUS}} \neq> \\
\mathrm{SP}_{\mathrm{GER}}\end{array}$ & 0.068 & 5.908 & 3.963 & 2.511 \\
\hline $\mathrm{SP}_{\mathrm{AUS}} \neq>\mathrm{SP}_{\mathrm{UK}}$ & 0.0860 & 5.849 & 4.116 & 2.864 \\
\hline \multicolumn{5}{|c|}{ Second Sub-Period (1992:10:W3-2001:08:W4) } \\
\hline $\begin{array}{c}\mathrm{SP}_{\mathrm{FRA}} \neq> \\
\mathrm{SP}_{\mathrm{AUS}}\end{array}$ & 1.769 & 7.818 & 5.627 & 4.920 \\
\hline $\begin{array}{c}\mathrm{SP}_{\mathrm{GER}} \neq> \\
\mathrm{SP}_{\mathrm{AUS}}\end{array}$ & 1.208 & 7.464 & 4.869 & 4.198 \\
\hline $\mathrm{SP}_{\mathrm{UK}} \neq>\mathrm{SP}_{\mathrm{AUS}}$ & $8.035^{* *}$ & 8.133 & 5.548 & 4.332 \\
\hline $\begin{array}{c}\mathrm{SP}_{\mathrm{AUS}} \neq> \\
\mathrm{SP}_{\mathrm{FRA}}\end{array}$ & 1.734 & 7.718 & 5.484 & 4.418 \\
\hline $\begin{array}{c}\mathrm{SP}_{\mathrm{AUS}} \neq> \\
\mathrm{SP}_{\mathrm{GER}}\end{array}$ & 0.013 & 11.401 & 5.755 & 4.773 \\
\hline $\mathrm{SP}_{\mathrm{AUS}} \neq>\mathrm{SP}_{\mathrm{UK}}$ & 3.510 & 11.146 & 5.818 & 4.721 \\
\hline
\end{tabular}

Notes:

(a) The notation $\neq>$ implies non-Granger causality.

(b) MWALD represents the modified Wald test statistic as described in equation (7).

(c) The lag order of the VAR model, $p$, was set to one for this sub-period. Also the augmentation lag, $d$, was set to one since each variable contains one unit root.

\section{Conclusions}

In this paper, we examine the causal links between the equity markets of Australia and the EU countries of the UK, Germany and France based on the Toda-Yamamoto (1995) causality test. Rather than making the strong assumption of unchanging normally distributed errors for determining our critical values, we allow for nonnormal error terms with time-varying autoregressive conditional heteroscedasticity (ARCH) for determining them. We find that doing so is important in dealing with financial data, as volatility in asset prices does appear to change over time, and otherwise there is not much basis for assuming normality. To deal with non-normal ARCH error processes, we resort to using leveraged bootstrap distributions, which 
Hacker and Hatemi-J (2002) suggest would work quite well under such circumstances.

We examine the period 1988 to 2001 using MSCI weekly data and had divided the sample into sub-samples because tests for parameter stability showed that the economic process has changed. Our results show no causal links between Australia and the EU countries during the period before the ERM crisis. After the ERM crisis, still no causal links exist between Australia and the countries of Germany and France but there was one between Australia and the UK with the causality running from the latter to the former but not vice versa. This result conforms to earlier findings in the literature. Thus, the Australian equity market offers diversification benefits to German and French, but not British, investors. The same benefit can also be derived by Australian investors in the German and French, but not the UK, equity markets. 


\section{Endnotes}

${ }^{1}$ Australia was hardly affected at all by the Asian crisis. Since 2000, Australia has been the fastest growing economy among the OECD countries (see IMF World Economic Outlook, 2002).

${ }^{2}$ See, Roca (2000).

${ }^{3}$ See Samant (1999).

${ }^{4}$ See Shapiro (1999), pp. 104-107 for a concise treatment of the ERM crisis.

${ }^{5}$ The existence of structural break was confirmed by tests for parameter stability.

${ }^{6}$ Elton and Gruber (1995) show that even if risk-adjusted returns in the foreign market is lower than that of the domestic market, it still pays to diversify provided the correlation is low enough. The riskadjusted returns in the foreign market need only to be above a certain proportion of the domestic riskadjusted return where the proportion is the correlation coefficient. This is more formally sated as follows:

$$
\begin{aligned}
& \frac{\bar{R}_{F}-r_{R F}}{\sigma_{F}}>\frac{\bar{R}_{D}-r_{R F}}{\sigma_{D}} \rho_{F \cdot D} \text {, or } \\
& \bar{R}_{F}-r_{R F}>\left[\bar{R}_{D}-r_{R F}\right] \times\left[\frac{\sigma_{F} \rho_{F \cdot D}}{\sigma_{D}}\right]
\end{aligned}
$$

where :

$r_{R F} \equiv$ risk free rate,

$\rho_{F . D} \equiv$ correlation between returns in foreign and domestic markets in investor's currency, $\bar{R}_{D} \equiv$ domestic returns (investor's market),

$\bar{R}_{F} \equiv$ returns on foreign investment in investor's currency,

$\sigma_{F} \equiv$ standard deviation of returns in foreign market,

$\sigma_{D} \equiv$ standard deviation of returns in domestic market.

${ }^{7}$ By causality, we mean causality in the Granger sense. That is, we are interested to find out whether one variable precedes another variable or not.

${ }^{8}$ For more details on leverage adjustment, see Davison, and Hinkley (1999) and Hacker and Hatemi-J (2002). The latter authors introduce this adjustment for multivariate equation cases.

${ }^{9}$ A program procedure written in Gauss to conduct leveraged bootstrap simulations is available on request from the authors. 


\section{References}

Adler, M. and B. Dumas (1983). "International Portfolio Choice and Corporation Finance: A Synthesis”, Journal of Finance, 38, pp. 925-984.

Agmon, T. (1972). "The Relations Among Equity Markets: A Study of Share Price Co-Movements in the United States, United Kingdom, Germany and Japan”, Journal of Finance, 4, pp. 839-1317.

Bailey, W. and R. Stulz (1990). "Benefits of International Diversification: The Case of Pacific Basin Stock Markets”. Journal of Portfolio Management, Summer, pp. 57-61.

Chow, G. (1960) "Tests of Equality Between sets of Coefficients in Two Linear Regressions”, Econometrica, 28, pp. 591-605.

Chowdhury, A.R. (1994). "Stock market Interdependence: Evidence from the Asian NIEs”, Journal of Macroeconomics, 19, 2, pp. 285-304.

Davison, A. C., and Hinkley, D.V. (1999) Bootstrap Methods and Their Application. Cambridge University Press. Cambridge, UK.

Department of Foreign Affairs and Trade (DFAT) (2001). The APEC Region Trade and Investment. Canberra: Australian Government Publishing Service

Efron, B. (1979) Bootstrap Methods: Another Look at the Jackknife, Annals of Statistics 7, pp. 1-26.

Espitia, M. and R. Santamaria (1994). "International Diversification Among the Capital Markets of the EEC”, Applied Financial Economics, 4, 1, pp. 1-10.

Eun, C. and S. Shim (1989) "International Transmission of Stock Market Movements”, Journal of Financial and Quantitative Analysis, 24, 2, pp. 241256.

Fischer, K. and A. Palasvirta (1990). "High Road to a Global Marketplace: The International Transmission of Stock Market Fluctuations”, Financial Review, 25, 371-94

Granger, C. W. J, (1969) "Investigating Causal Relations by Econometric Models and Cross Spectral Methods”, Econometrica, 37, pp. 424-438.

Granger, C.W.J. and O. Morgenstern (1970). Predictability of Stock Market Prices. Lexington, MA: Heath Lexington Books.

Grubel, H.G. (1968). "Internationally Diversified Portfolios: Welfare Gains and Capital Flows”, American Economic Review, 58, 5, pp. 1299-1314.

Hacker R. S. and Hatemi-J, A. (2002) "The Size Properties of Toda-Yamamoto Test Statistics for Causality Using Asymptotic and Bootstrap Distributions” submitted for publication.

Hamao, Y., R.W. Masulis, and V. Ng (1990). "Correlations in Price Changes and Volatility Across International Stock Markets", The Review of Financial Studies, 3, 2, pp. 281-307.

Hatemi-J, A. (2002) "A New Method to Choose the Optimal Lag Order in Stable and Unstable VAR Models”. Applied Economics Letters, forthcoming.

Hillard, J. E. (1979). "The Relationship Between Equity Indices on World Exchanges”, .Journal of Finance, 34, 1, pp. 103-114.

IMF World Economic Outlook, 2002, Washington DC: International Monetary Fund.

Janakiramanan, S. and A.S. Lamba (1998). “An Empirical Examination of Linkages Between Pacific-Basin Stock Markets”, Journal of International Financial Markets, Institutions and Money, 8, 2, pp. 155-173. 
Makridakis, S.G. and S.C. Wheelwright (1974). "An Analysis of the Interrelationships Among World Stock Exchanges”, Journal of Business Finance \& Accounting, 1, pp. 195-215.

Malliaris, A.G. and J.L. Urrutia (1992). "The International Crash of October 1987: Causality Tests”, Journal of Financial and Quantitative Analysis, 27, 3, pp. 353-364.

Markowitz, H. (1959). Portfolio Selection: Efficient Diversification of Investments. New York: John Wiley.

Masih, A.M.M. and R. Masih (1999). “Are Asian Stock Market Fluctuations Due Mainly to Intra-Regional Contagion Effects? Evidence Based on Asian Emerging Stock Markets”, Pacific Basin Finance Journal, 7, 3-4, pp. 251-282.

McNelis, P.D. (1993). "The Response of Australian Stock, Foreign Exchange, and Bond Markets to Foreign Asset Returns and Volatilities”, Research Discussion Paper, Economic Research Department, Reserve Bank of Australia.

OECD (2001 and 2002). OECD Economic Bulletin, Paris: Organisation for Economic Cooperation and Economic Development.

Park, J. and A.M. Fatemi (1993). "The Linkages Between the Equity Markets of Pacific-Basin Countries and those of the US, UK and Japan: A Vector Autoregression analysis”, Global Finance Journal, 4, 1, pp. 49-64.

Perron, P., 1989. The great crash, the oil price shock and the unit root hypothesis, Econometrica 57, pp. 1361-1401.

Roca, E. (1999) "Short-Term and Long-Term Price Linkages between the Equity Markets of Australia and Its Major Trading Partners", Applied Financial Economics, 9, pp. 501-11.

Roca, E. (2000). Price Interdependence Among Equity Markets in the Asia-Pacific Region. Aldershot, UK: Ashgate Publishing.

Samant, A. (1999). "Risk-Adjusted Return in European Industrial Stocks: A Global Investor's Perspective”, International Journal of Commerce and Management, 9, 1\&2, pp. 1-19.

Shapiro, A.C. (1999). Multinational Financial Management, $6^{\text {th }}$ ed., New Jersey: Prentice Hall.

Sheng, H.C. and A.H. Tu (2000). “A Study of Cointegration and Variance Decomposition Among National Equity Market Indices Before and During the Period of the Asian Financial Crisis”, Journal of Multinational Financial Management, 10, 3-4, pp. 345-365.

Smith, K. L.; J. Brocato, and J.E. Rogers (1995). “An Analysis of World Capital Market Return/Risk Ratios: A Test of Global Financial Integration During the 1980-1991 Period”, Managerial Finance, 21, 8, pp. 13-31.

Solnik, B.; C. Boucrelle and Y.L. Fur (1996). "International Market Correlation and Volatility”, Financial Analysts Journal, September-October, pp. 17-34.

To, M.C.; K.G. Assoe; and S. Pariente (1994). "The Efficiency of Emerging Stock Markets and Their Relationships with the World's Major Stock Exchanges”, Montreal: CETAI University of Montreal.

Toda, H. Y. and Yamamoto, T. (1995) Statistical Inference in Vector Autoregressions with Possibly Integrated Processes. Journal of Econometrics, 66, pp. 225-250.

Wheatley, S. (1988), “Some Tests of International Equity Market Integration”, Journal of Financial Economics, 21, pp. 177-212. 